\title{
Small discoveries can have great consequences in love affairs: The case of "Beauty and the Beast"
}

Sergio Rinaldi (rinaldi@iiasa.ac.at)

Pietro Landi

Fabio Della Rossa

\section{Approved by}

Ulf Dieckmann

Director, Evolution and Ecology Program

June 2015 


\title{
Small discoveries can have great consequences in love affairs: The case of Beauty and The Beast
}

\author{
Sergio Rinaldi \\ Dipartimento di Elettronica, Informazione e Bioingegneria, Politecnico di Milano, \\ Via Ponzio 34/5, 20133 Milano, Italy.
}

Evolution and Ecology Program, International Institute for Applied Systems Analysis, 2361 Laxenburg,

Austria.

sergio.rinaldi@polimi.it

Pietro Landi

Dipartimento di Elettronica, Informazione e Bioingegneria, Politecnico di Milano, Via Ponzio 34/5, 20133 Milano, Italy.

Fabio Della Rossa

Dipartimento di Elettronica, Informazione e Bioingegneria, Politecnico di Milano, Via Ponzio 34/5, 20133 Milano, Italy.

\begin{abstract}
A mathematical model is proposed for interpreting the love story portrayed by Walt Disney in the film "Beauty and The Beast". The analysis shows that the story is characterized by a sudden explosion of sentimental involvements, revealed by the existence of a saddle-node bifurcation in the model. The paper is interesting not only because it deals for the first time with catastrophic bifurcations in specific romantic relationships, but also because it enriches the list of examples in which love stories are satisfactorily described through Ordinary Differential Equations.
\end{abstract}

Keywords: love dynamics, mathematical models, dynamical systems, catastrophic bifurcations, saddle-node bifurcations, Beauty and The Beast. 


\section{Introduction}

2 Love stories are dynamical processes that develop in time starting, in general, from a state of indifference. They reach a stationary, cyclic, or chaotic regime where they often remain for a long time before fading

4 or being interrupted by the disappearance of one of the partners [Rey, 2010]. The evolution of romantic relationships is marked by all typical features known in nonlinear system theory.

Numerous love stories tend, sometimes after turbulent transients, towards a stationary regime where the involvements of the two partners remain practically constant. One of the most known examples of this kind is the story between Scarlett and Rhett described in "Gone with the Wind" [Mitchell, 1936] that has inspired the most popular film of the entire cinematographic history. A cyclic love story between a poet

10 (Francesco Petrarca) and his mistress (Laura De Sade) is described in the "Canzoniere" [Petrarca, 1374], the most celebrated collection of love poems in western culture [Jones, 1995]. Among the numerous chaotic

${ }_{12}$ love stories reported in literature, perhaps the most interesting one is described in "Jules et Jim" [Roché, 1953], a novel that became famous after the release in 1962 of the homonymous film by François Truffaut, one of the leaders of the Nouvelle Vague.

The existence of alternative stable states (each one with its basin of attraction) - a typical property of

${ }_{16}$ nonlinear dynamical systems - is detectable in many romantic relationships. Indeed, it is known that the quality of pairwise relationships can drop from a high to a low regime and remain there for a long time, if

18 not forever, after the temporary infatuation of one of the two partners for another person. An important example of a couple with alternative stable states is described in "Cyrano de Bergerac" [Rostand, 1897],

20 the masterpiece of romantic French literature, where it is shown how difficult it can be to jump from an unfavorable sentimental regime into the basin of attraction of a more favorable (and, hence, more desirable) 22 regime.

Another important feature of nonlinear dynamical systems is the possibility that very small (in the

24 limit not perceivable) variations of some strategic parameter are associated with relevant discontinuities in the feelings of the partners. In other words, small discoveries can have great consequences in love affairs.

26 From a formal point of view these discontinuities are nothing but catastrophic bifurcations [Strogatz, 1994]. They are important because they are, in general, associated with great emotions, emerging when there are

28 dramatic breakdowns or enthusiastic explosions of interest. Potential examples of the first kind are all relationships prevalently based on sex. Indeed, sexual appetite inexorably decreases in time [Rinaldi et al.,

so 2012] so that a point of unavoidable and unexpected separation can easily be reached if the individuals are mainly interested in sex. A well known example of the second kind is that of a playboy who systematically 32 insists in reinforcing his appeal until his prey suddenly falls in love with him.

All above properties, as well as others, can be well understood by putting them in a rational frame 34 through the use of mathematical models. This is what has been done up to now. First, a naive model has been studied by Strogatz [1988] in a seminal paper and, then, the analysis has been extended to a series of

36 more general abstract models of romantic relationships [Gragnani et al., 1997; Rinaldi, 1998b; Rinaldi \& Gragnani, 1998a,b; Sprott, 2004, 2005; Rinaldi et al., 2010]. Complex issues involving optimal control theory

${ }_{38}$ [Feichtinger et al., 1999; Rey, 2010], time-delays [Liao \& Ran, 2007; Son \& Park, 2011], fractional-order derivatives [Ahmad \& El-Khazali, 2007; Ozalp \& Koca, 2012], and time-varying parameters [Sprott, 2005;

${ }_{40}$ Wauer et al., 2007; Barley \& Cherif, 2011] have also been taken into account as well as love stories involving more than two individuals [Dercole, 1999; Sprott, 2004; Bellomo \& Carbonaro, 2006; Ahmad \& El-Khazali,

42 2007; Bellomo \& Carbonaro, 2008] However, we must admit that in order to reinforce the analysis and make it more convincing, it is desirable, if not mandatory, to refer to specific and well documented romantic

${ }_{44}$ relationships, because the possibility of successfully describing a complex love story with a mathematical model can not be given as granted. In this respect, the existing literature is still quite poor, because only

46 three studies, where love stories are satisfactorily described with mathematical models, are available today. They deal with "Gone with the Wind" [Rinaldi et al., 2013], the "Canzoniere" [Rinaldi, 1998a] and "Jules ${ }_{48}$ et Jim" [Dercole, 1999]. Moreover, modeling studies dealing with specific love stories characterized by catastrophic bifurcations have never been carried out so far. To cover these deficiencies, we present in this 50 paper the detailed study of the well known love story depicted by Walt Disney in "Beauty and The Beast". 


\section{The model}

2 The majority of the models proposed in the past for the description of love stories are composed of two Ordinary Differential Equations (ODEs), one for each partner, i.e.,

$$
\begin{aligned}
& \dot{x}_{1}(t)=f_{1}\left(x_{1}(t), x_{2}(t), A_{2}\right) \\
& \dot{x}_{2}(t)=f_{2}\left(x_{1}(t), x_{2}(t), A_{1}\right) .
\end{aligned}
$$

4 In these models the state variables $x_{i}(t), i=1,2$, are the feelings at time $t$ of the individuals for their partner (see [Gottman et al., 2002] for a relevant exception), while $A_{1}$ and $A_{2}$ are their appeals. The appeals, 6 as well as all other parameters specifying the psychical characteristics of the individuals, are assumed to be time-invariant. In accordance with Levinger [1980], positive values of the feelings range from sympathy

8 to passion, while negative values are associated with antagonism and disdain. In a number of contributions it is shown how model (1) can be conceptually justified and potentially derived from the general theory

10 of stochastic processes [Carbonaro \& Serra, 2002; Carbonaro \& Giordano, 2005; Bellomo \& Carbonaro, 2006, 2008] or from very general principles, like those of Quantum Mechanics [Bagarello \& Oliveri, 2010;

12 Bagarello, 2011]. However, from an operational point of view, this approach for deriving model (1) does not seem to be very promising if the aim of the study is to model specific love stories in some details. This

${ }_{14}$ is why in the majority of the contributions, as well as in this paper, the functions $f_{i}, i=1,2$, appearing in model (1), are empirically defined as the unbalance between regeneration and consumption flows, as 16 explained below.

The appeal of individual $i$ has various components $A_{i}^{h}$ like physical attractiveness, age, altruism, richness and others, which are independent of the feeling $x_{i}$. If $\lambda_{j}^{h}$ is the weight that individual $j(j \neq i)$ gives to the $h$-th component of the appeal of his/her partner, we can define the appeal of $i$ (perceived by j) as

$$
A_{i}=\sum_{h} \lambda_{j}^{h} A_{i}^{h}
$$

Thus, the appeal is not an absolute character of the individual, but rather a value perceived by his/her 18 present or future partner.

Two persons meeting for the first time at $t=0$, are, in general, indifferent one to each other, i.e. $20 x_{1}(0)=x_{2}(0)=0$. Then, the feelings evolve in accordance with equations (1) where the rates of change $f_{i}$ are dictated by the unbalance between regeneration and consumption processes.

The consumption process, called oblivion, explains why individuals gradually lose memory of their partners after separating. As done in almost all fields of science, losses are assumed to occur at exponential ${ }_{24}$ rate, i.e., $x_{i}(t)=x_{i}(0) \exp \left(-\alpha_{i} t\right)$ or, equivalently, in terms of ODEs, $\dot{x}_{i}(t)=-\alpha_{i} x_{i}(t)$, where $\alpha_{i}$ is the so-called forgetting coefficient. In contrast, the regeneration processes are of two distinct kinds, namely ${ }_{26}$ reaction to appeal and reaction to love. The flow of interest generated in individual $j$ by the appeal of the partner is obtained by multiplying $A_{i}$ by a factor $\rho_{j}$ identifying the sensitivity of individual $j$ to appeal, 28 while the second regeneration process, the reaction to the love of the partner, is described by a function $R_{i}\left(x_{j}\right)$. The most standard individuals, usually called secure, are those who like to be loved. An individual

so $i$ belonging to this class is formally characterized by an increasing function $R_{i}\left(x_{j}\right)$ that identifies the flow of interest generated in individual $i$ by the love $x_{j}$ of the partner. In the first studies on love dynamics, 2 reaction functions of secure individuals were linear [Strogatz, 1988; Rinaldi, 1998b], while, later, they have been assumed to be bounded [Rinaldi \& Gragnani, 1998a; Rinaldi et al., 2010], as shown in Fig. 1. The ${ }_{34}$ reason for this change is that unbounded functions do not capture the psychophysical limitations present in all individuals.

Thus, in conclusion, a reasonable model for couples of secure individuals is

$$
\begin{aligned}
& \dot{x}_{1}(t)=-\alpha_{1} x_{1}(t)+\rho_{1} A_{2}+R_{1}\left(x_{2}\right) \\
& \dot{x}_{2}(t)=-\alpha_{2} x_{2}(t)+\rho_{2} A_{1}+R_{2}\left(x_{1}\right) .
\end{aligned}
$$

The reason why we limit our attention to model (2) with increasing and saturating reaction functions (see

Fig. 1) is that such a model is perfectly suited for mimicking the characters of Beauty and The Beast. All 


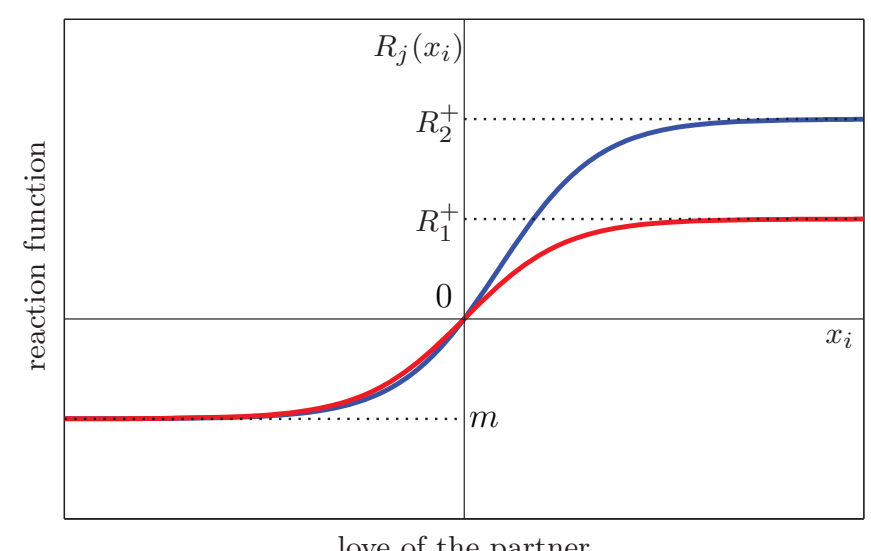

Fig. 1. Typical reaction functions $R_{1}\left(x_{2}\right)$ (red) and $R_{2}\left(x_{1}\right)$ (blue) of two secure individuals (see [Rinaldi et al., 2010]). The two graphs correspond to $R_{1}\left(x_{2}\right)=\frac{e^{x_{2}}-e^{-x_{2}}}{e^{x_{2}} / R_{1}^{+}-e^{-x_{2}} / R_{1}^{-}}$and $R_{2}\left(x_{1}\right)=\frac{e^{x_{1}}-e^{-x_{1}}}{e^{x_{1}} / R_{2}^{+}-e^{-x_{1}} / R_{2}^{-}}$; with $R_{1}^{+}=1, R_{2}^{+}=2$, and $R_{1}^{-}=R_{2}^{-}=-1$.

properties of model (2), including bifurcations, are summarized below. They have been derived through 2 numerical bifurcation analysis and thoroughly discussed in Rinaldi et al. [2010], where the interested reader can find all details.

Model (2), as well as any other realistic model, says that if the two individuals are indifferent one to each other when they meet for the first time at $t=0$, the story is initially dominated by the appeals, since

$$
\dot{x}_{1}(0)=\rho_{1} A_{2}, \dot{x}_{2}(0)=\rho_{2} A_{1} .
$$

${ }_{4}$ Thus, in particular, the story has a positive start, in the sense that $x_{i}(t)>0, i=1,2$, for all sufficiently low values of $t$, if and only if both individuals are appealing, as shown in Fig. 2a. At first glance, this seems

6 to suggest that non appealing persons cannot be loved by other persons, a rather crude conclusion which is in contrast with real life observations. Indeed, there are plenty of individuals perceived as non appealing

8 but living steadily in a high quality relationship. This apparent conflict between model and life is due to two different reasons, one trivial and one subtle.

The trivial reason is that, as already remarked, the appeal is not an absolute character of an individual but rather a subjective value perceived by the partner. Thus, given as granted that high perceptions of the

12 appeals promote the development of high quality feelings in a couple, it is not so important to be judged as appealing by the majority of the people of a given community, but rather to be appreciated by the partner.

${ }_{14}$ This explains why individuals perceived as non appealing in their community can be involved in positive love stories.

16 The second reason for the apparent conflict between model and life is more subtle as explained below. It is related with the fact that dynamical systems can have long term behaviors which have only little to 18 share with short time behaviors. In particular, the signs of the feelings in the long term can be different from those characterizing the initial phase of the romantic relationship. In the case of model (2) the divergence

${ }_{20}$ (equal to $-\left(\alpha_{1}+\alpha_{2}\right)$ ) does not change sign, so that the attractors (capturing the long term behaviors of the system) can only be equilibria - limit cycles being excluded by Bendixon's theorem [Strogatz, 1994].

${ }_{22}$ The detailed analysis of model (2) [Rinaldi et al., 2010] shows that there are two alternative stable states if the appeals are relatively low, i.e., if they belong to the compact white region in Fig. 2b, from now on

${ }_{24}$ called ASS (Alternative Stable States). In contrast, when the point $\left(A_{1}, A_{2}\right)$ does not fall in ASS only one stable equilibrium exists and the signs of its components are as indicated in Fig. 2b. Obviously, the signs

26 of the feelings can be specified also in region ASS if reference is made to only one of the two alternative stable states. For example, if reference is made to the equilibrium reached when the two individuals are

${ }_{28}$ initially indifferent one to each other, the signs of the feelings in the long term are as indicated in Fig. 2c. Figure 2c points out a very important property: couples with positive appeals are guaranteed to evolve so toward a high quality relationship, but this is possible also for many other couples in which one of the two 
individuals is not appealing. In conclusion, the comparison of Fig. 2a with Fig. 2c supports the following important statement: "love stories involving individuals who are not appealing can develop positively after an initial phase of antagonism" or, more crudely, "individuals can be happy in the long term even if they are not appealing".

(a)

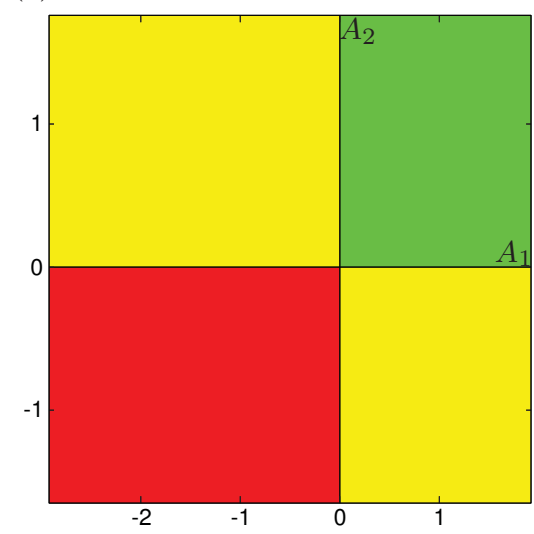

(b)

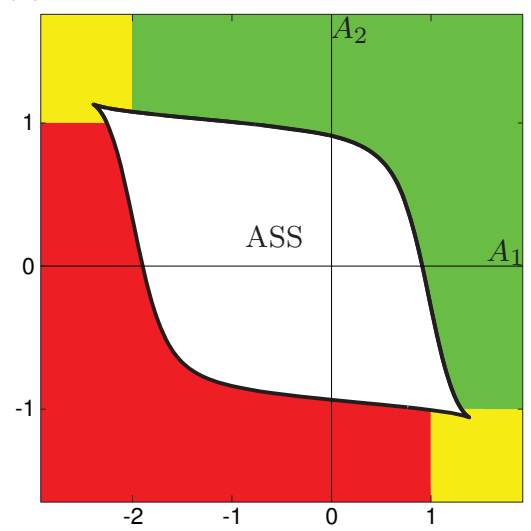

(c)

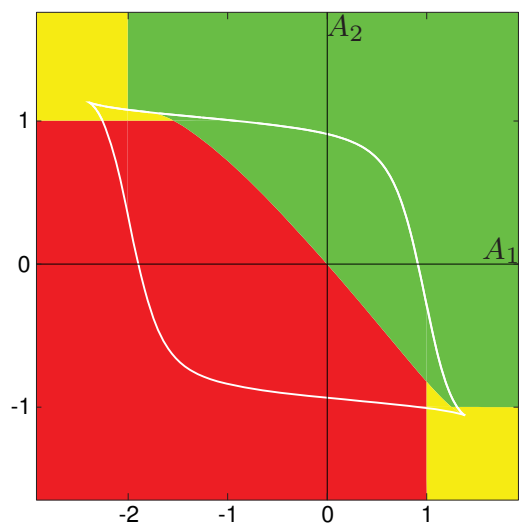

Fig. 2. The signs of the feelings in model (2) for all possible values of the appeals $A_{1}$ and $A_{2}$. In the green [red] regions the appeals are both positive [negative], while in the yellow regions they are of opposite sign. Parameter values are $\alpha_{1}=0.1$, $\alpha_{2}=0.3, \rho_{1}=\rho_{2}=1$, and reaction functions are as in Fig. 1. (a) The signs of the feelings during the initial phase of the love story. (b) The signs of the feelings in the long term. In the white region ASS the signs cannot be specified because in that region there are two alternative stable equilibria. (c) The signs of the feelings in the long term when the two individuals are initially indifferent one to each other.

As shown in [Rinaldi et al., 2010], the points of the boundary of ASS are saddle-node bifurcation points [Strogatz, 1994] and there are no other catastrophic bifurcations in the system. More precisely, for $\left(A_{1}, A_{2}\right)$ in region ASS there are three equilibria $x^{\prime}, x^{\prime \prime}$, and $x^{\prime \prime \prime}$ that are ordered from low to high, in the sense that $x^{\prime}<x^{\prime \prime}<x^{\prime \prime \prime}$. The intermediate equilibrium $x^{\prime \prime}$ is always unstable (a saddle), while the two others are stable. On the lower boundary of ASS $x^{\prime \prime}=x^{\prime \prime \prime}$, while on the upper boundary of the same region $x^{\prime}=x^{\prime \prime}$. 10 Thus, consider a couple represented by a point $\left(A_{1}, A_{2}\right)$ in region ASS close to its upper boundary and assume that the couple is in its unfavorable stable state $x^{\prime}$. Then, if one or both appeals increase by a small amount, the new point $\left(A_{1}, A_{2}\right)$ will be just above the upper boundary of ASS where the favorable state $x^{\prime \prime \prime}$ is the unique equilibrium point, as shown in Fig. $2 \mathrm{~b}$. This means that a very small variation of 14 the appeal can trigger a remarkable variation in the feelings - the transition from the unfavorable to the favorable state.

Many real love stories reported in the technical literature, as well as many fictitious stories portrayed in novels and films, show that catastrophic transitions are frequent. This is because the appeals can vary

18 slowly over time due to ageing or adaptation, or because a series of small discoveries can force one of the two individuals to gradually change his/her perception of the appeal of the partner. This is exactly the

20 case described in the next section, where Beauty discovers the moral appeal of The Beast through a series of specific events, up to the point of being entrained in an inevitable phase of explosion of interest.

\section{3. Beauty and The Beast}

"Beauty and The Beast" (BB) is one of the most famous European fairy tales (the first trace can be found 24 in the "Metamorfosi" by Lucio Apuleio (125-175 AD)). The most popular version, written in French by Jeanne-Marie Leprince de Beaumont in 1756, has been transformed into films (the first directed by Jean

${ }_{26}$ Cocteau in 1946), cartoons, and musicals. Here we refer to the 1991 Walt Disney's realization that got a nomination for the best film and was awarded with two Oscars (soundtrack and original song).

Twelve short segments of the film (BB1,..,BB12) are described below to support the mathematical interpretation of the love story involving Beauty and The Beast. Snapshots of the twelve film segments 
are shown in the panels of Fig. 3 where the initial and final times of each segment are reported in the corresponding panel.

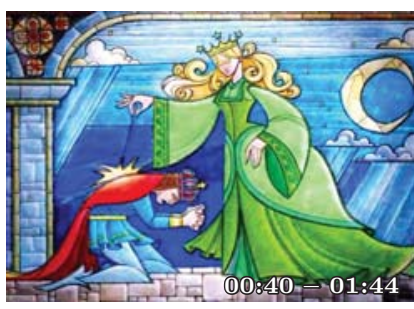

(BB1) Foreword

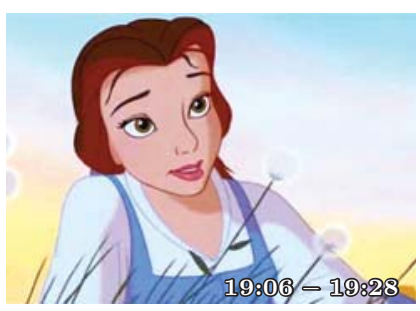

(BB2) The grace of Beauty

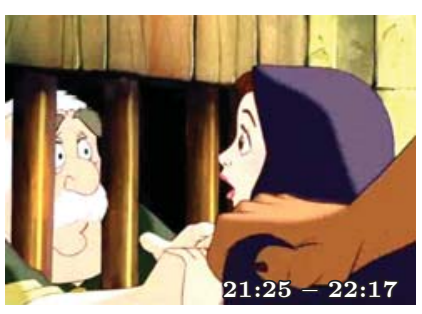

(BB3) The excha

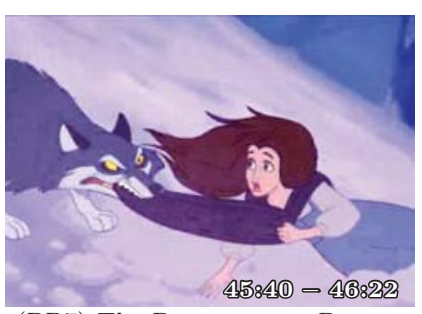
from the wolves

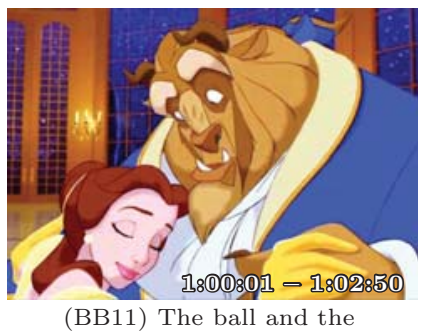
statement of happiness

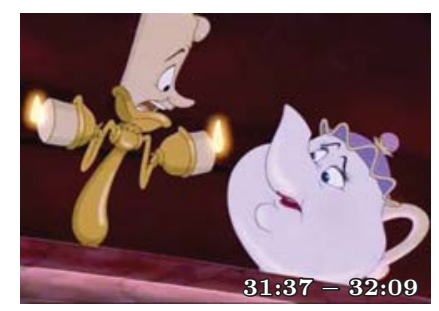

(BB4) The Beast's friends suggestion

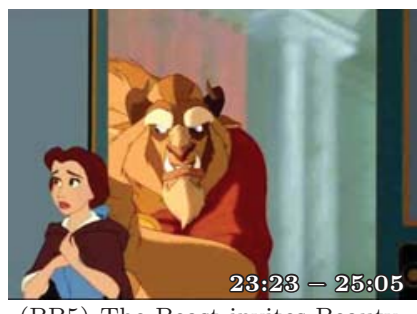
for dinner

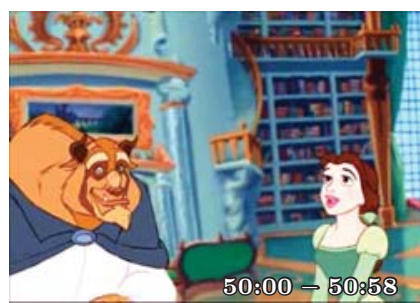

(BB9) The Beast offers Beauty the access to the library
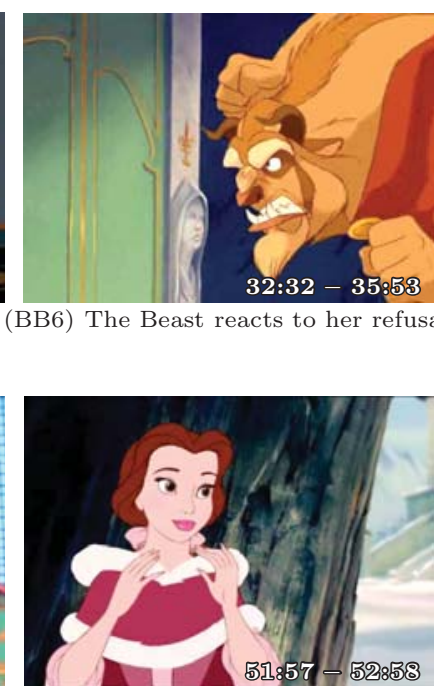

(BB10) The first symptoms of Beauty's involvement

Fig. 3. Snapshots of the twelve film segments home.dei.polimi.it/rinaldi/BeautyAndTheBeast/film.html

$(\mathrm{BB} 1, \ldots, \mathrm{BB} 12) \quad$ described

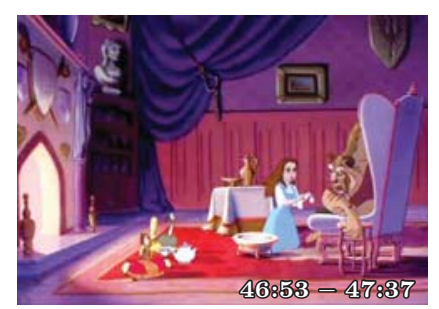

(BB8) Beauty cures The Beast and thanks him

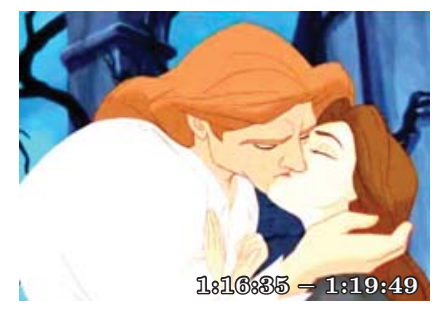

(BB12) The fairy transforms The Beast into a prince

in the text. Source:

The film begins (BB1) with a short foreword: For punishment a young prince is transformed by a 4 fairy into a physically repelling beast. He will recover his human aspect only if a young lady will explicitly declare to be in love with him. Beauty, a very happy and pretty girl (BB2), obtains from The Beast the

permission to replace her father who is too old to bear the pains of imprisonment (BB3). The Beast's friends suggest that Beauty is a unique opportunity for him to regain his original aspect (BB4). Thus, The

$\&$ Beast starts, in his own way, to woo her. First, he transfers her from the prison in the tower of the castle to a beautiful room, and then invites her to dinner (BB5), in truth with crude modes of behavior. But Beauty

10 refuses the invitation with disdain (BB6). Some time later, Beauty, attacked in the woods by a horde of wolves, is rescued by The Beast who shows with great courage that he is ready to sacrifice himself for

${ }_{12}$ her (BB7). Taking care of his wounds, Beauty thanks him, demonstrating for the first time a slightly less hostile attitude towards him (BB8). Encouraged by this sign, The Beast offers her access to the beautiful

${ }_{14}$ castle library, a gift that she definitely appreciates (BB9). It is after this gesture that Beauty perceives the altruism of The Beast, and a little later, in an idyllic scene, she shows the first signs of involvement with

${ }_{16}$ him (BB10). The inevitable transition to a state of reciprocated love has already started and culminates with the dance in the great hall of the castle during which she rests her head graciously on his chest and

18 admits to being happy (BB11). At this point the story finishes, with Beauty happy in spite of the still repelling physical aspect of The Beast. To crown the fairy tale the last scene (BB12) shows The Beast

${ }_{20}$ dying in the arms of Beauty, who declares her love to him, thus triggering the magic of his transformation into a prince. 
(a)

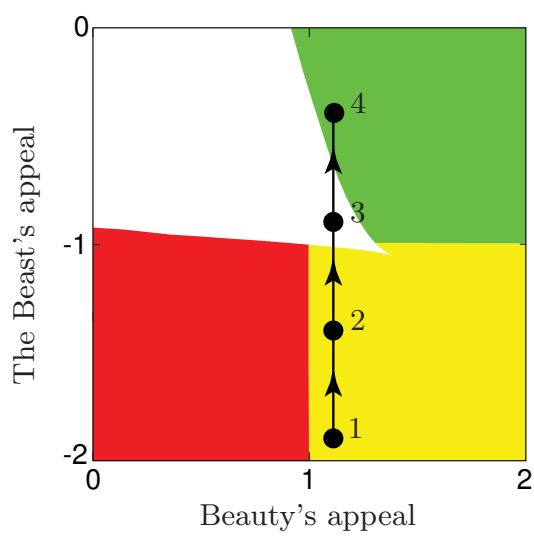

(b)

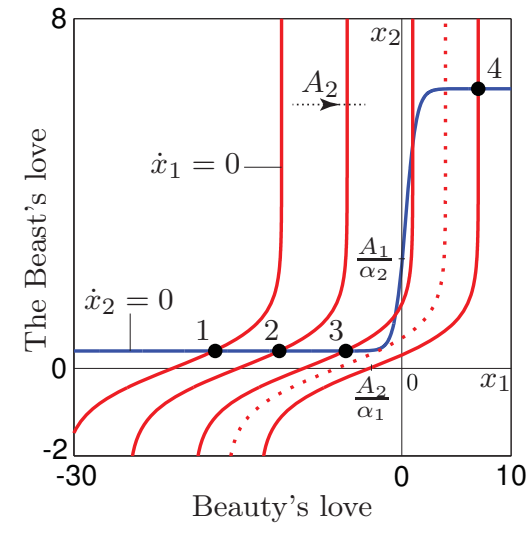

(c)

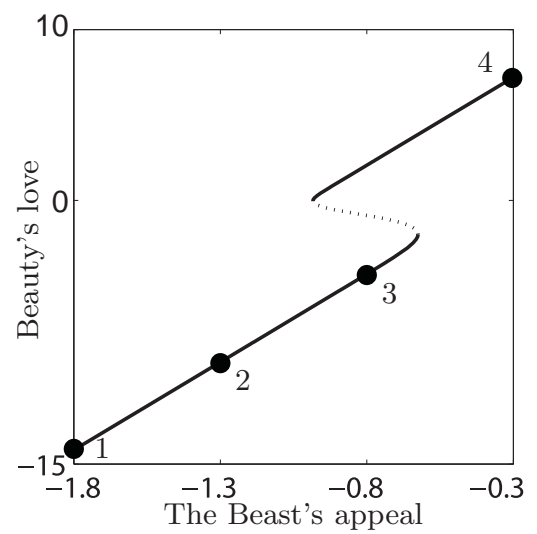

Fig. 4. Interpretation of the love story between Beauty and The Beast with model (2). Points $1, \ldots, 4$ indicate the different values of the appeals during the story and the corresponding values of the feelings at equilibrium. (a) The Beast's appeal (perceived by Beauty) varies during the story because she becomes gradually aware of his altruism through a series of small discoveries (point 2: BB5; point 3: BB7; point 4: BB9). (b) The null-cline $\dot{x}_{1}=0$ of model (2) shifts to the right when $A_{2}$ is increased, while the null-cline $\dot{x}_{2}=0$ remains unchanged. The dotted null-cline corresponds to the saddle-node bifurcation. (c) Beauty's love at equilibrium as a function of The Beast's appeal. The dotted segment of the curve corresponds to saddle equilibria.

The love story just described can be perfectly interpreted with model (2) provided suitable values are 2 assigned to the appeals of the two lovers. Beauty's appeal $A_{1}$ is definitely high (BB2) and remains such during all the story. The appeal of The Beast (perceived by Beauty) $A_{2}$ has a negative component due 4 to his repelling physical aspect and a positive component due to his altruism. The negative component is large and fixed, while the positive component increases over time because it is gradually discovered by

6 Beauty through a series of specific events $(B B 5,7,9)$ (In reality, in the film there are also other episodes (not mentioned here for shortness) during which Beauty has the chance of appreciating the altruism of The Beast). It is therefore licit to imagine that the evolution of the love story is the result of a slow variation of the appeals along the path indicated in Fig. 4a. At the beginning of the story (point 1 in Fig. 4a) - soon 10 after Beauty and The Beast have met-her feeling at equilibrium is negative while his feeling is positive (yellow region in Fig. 4a). Then, when $A_{2}$ increases, nothing relevant occurs (in the sense that the signs of 12 the feelings remain unchanged) until the upper saddle-node bifurcation curve is crossed from below (BB9). This crossing triggers in the space of the feelings a relevant transition that ends at a positive equilibrium 14 (point 4 is in the green region in Fig. 4a) even if the appeal of The Beast is still negative (BB11).

The analysis of the null-clines reported in Fig. 4b for various values of $A_{2}$ and the graph of Beauty's 16 love versus The Beast's appeal reported in Fig. 4c are also interesting because they show that the feeling of Beauty increases progressively but remains negative until the catastrophic transition towards the positive 18 equilibrium (point 4 in Fig. 4b) occurs.

\section{Conclusions}

${ }_{20}$ We have shown that the evolution of a love story can be characterized by a sudden surprise due to the inevitable explosion of the feelings of the partners. This has been done by interpreting the Walt Disney's

${ }_{22}$ film "Beauty and The Beast" with a mathematical model characterized by a saddle-node bifurcation. The paper is interesting not only because it points out a catastrophic bifurcation in a specific love story, but

24 also because it enriches the list of examples in which love stories are successfully described with simple ODEs models [Rinaldi et al., 2013; Rinaldi, 1998a; Dercole, 1999]. Another study concerning catastrophic bifurcations in romantic relationships will be discussed in a companion paper dedicated to the mathematical analysis of the love story between Elizabeth and Darcy described in "Pride and Prejudice" [Austen, 1813]. 


\section{References}

2 Ahmad, W. M. \& El-Khazali, R. [2007] "Fractional-order dynamical models of love," Chaos, Solitons 83 Fractals 33, 1367-1375.

${ }_{4}$ Austen, J. [1813] Pride and Prejudice (T. Egerton, Whitehall, London, England).

Bagarello, F. [2011] "Damping in quantum love affairs," Physica A 390, 2803-2811.

- Bagarello, F. \& Oliveri, F. [2010] "An operator-like description of love affairs," SIAM Journal on Applied Mathematics 70, 3235-3251.

\& Barley, K. \& Cherif, A. [2011] "Stochastic nonlinear dynamics of interpersonal and romantic relationships," Applied Mathematics and Computation 217, 6273-6281.

10 Bellomo, N. \& Carbonaro, B. [2006] "On the modelling of complex sociopsychological systems with some reasoning about Kate, Jules, and Jim," Differential Equations and Nonlinear Mechanics 2006, 1-26.

${ }_{12}$ Bellomo, N. \& Carbonaro, B. [2008] "On the complexity of multiple interactions with additional reasoning about Kate, Jules, and Jim," Mathematical and Computer Modelling 47, 168-177.

${ }_{14}$ Carbonaro, B. \& Giordano, C. [2005] "A second step towards a stochastic mathematical description of human feelings," Mathematical and Computer Modelling 41, 587-614.

${ }_{16}$ Carbonaro, B. \& Serra, N. [2002] "Towards mathematical models in psychology: A stochastic description of human feelings," Mathematical Models and Methods in Applied Sciences 10, 1453-1490.

18 Dercole, F. [1999] "A modeling interpretation of the novel "Jules et Jim"," Master thesis, Department of Electronics and Information, Politecnico di Milano, Milano, Italy, (in Italian).

${ }_{20}$ Feichtinger, G., Jorgensen, S. \& Novak, A. [1999] "Petrarch's Canzoniere: Rational addiction and amorous cycles," Journal of Mathematical Sociology 23, 225-240.

22 Gottman, J. M., Murray, J. D., Swanson, C. C., Tyson, R. \& Swanson, K. R. [2002] The Mathematics of Marriage: Dynamic Nonlinear Models (Bradford Book, Massachussetts Institute of Technology).

${ }_{24}$ Gragnani, A., Rinaldi, S. \& Feichtinger, G. [1997] "Cyclic dynamics in romantic relationships," International Journal of Bifurcation and Chaos 7, 2611-2619.

${ }_{26}$ Jones, F. J. [1995] The Structure of Petrarch's Canzoniere: A Chronological, Psychological and Stylistic Analysis (Brewer, Cambridge, UK).

28 Levinger, G. [1980] "Toward the analysis of close relationships," Journal of Experimental Social Psychology 16, 510-544.

so Liao, X. \& Ran, J. [2007] "Hopf bifurcation in love dynamical models with nonlinear couples and time delays," Chaos, Solitons \& Fractals 31, 853865.

${ }_{32}$ Mitchell, M. [1936] Gone with the Wind (Macmillan Publishers, New York, USA).

Ozalp, N. \& Koca, I. [2012] "A fractional order nonlinear dynamical model of interpersonal relationships," Advances in Difference Equations 189, 510-544.

Petrarca, F. [1374] Rerum Vulgarium Fragmenta (Padova, Italy), (in Italian).

${ }_{36}$ Rey, J.-M. [2010] "A mathematical model of sentimental dynamics accounting for marital dissolution," PLOS ONE 5, e9881.

${ }_{38}$ Rinaldi, S. [1998a] "Laura and Petrarch: An intriguing case of cyclical love dynamics," SIAM Journal on Applied Mathematics 58, 1205-1221.

40 Rinaldi, S. [1998b] "Love dynamics: The case of linear couples," Applied Mathematics and Computation 95, 181-192.

${ }_{42}$ Rinaldi, S., Della Rossa, F. \& Dercole, F. [2010] "Love and appeal in standard couples," International Journal of Bifurcation and Chaos 20, 2443-2451.

${ }_{44}$ Rinaldi, S., Della Rossa, F. \& Fasani, S. [2012] "A conceptual model for the prediction of sexual intercourse in permanent couples," Archives of Sexual Behavior 41, 1337-1343.

${ }_{46}$ Rinaldi, S., Della Rossa, F. \& Landi, P. [2013] "A mathematical model of "Gone with the Wind", Physica $A$ (in press).

${ }_{48}$ Rinaldi, S. \& Gragnani, A. [1998a] "Love dynamics between secure individuals: A modeling approach," Nonlinear Dynamics, Psychology, and Life Sciences 2, 283-301.

so Rinaldi, S. \& Gragnani, A. [1998b] "Minimal models for dyadic processe: A review," The complex matters of mind, ed. Orsucci, F. (World Scientific, Singapore), pp. 87-104. 
Roché, H.-P. [1953] Jules et Jim (Gallimard, Paris, France), (in French).

2 Rostand, E. [1897] Cyrano de Bergerac (Fasquelle, Paris, France), (in French).

Son, W. \& Park, Y. [2011] "Time delay effect on the love dynamical model," Journal of the Korean Physical Society 59, 2197-2204.

Sprott, J. C. [2004] "Dynamical models of love," Nonlinear Dynamics, Psychology, and Life Sciences 8, $303-314$

Sprott, J. C. [2005] "Dynamical models of happiness," Nonlinear Dynamics, Psychology, and Life Sciences 9, 23-36.

Strogatz, S. H. [1988] "Love affairs and differential equations," Mathematics Magazine 61, 35.

10 Strogatz, S. H. [1994] Nonlinear Dynamics and Chaos (Addison-Wesley, Reading, Massachussets).

Wauer, J., Schwarzer, D., Cai, G. \& Lin, Y. [2007] "Dynamical models of love with time-varying fluctuations," Applied Mathematics and Computation 188, 1535-1548. 